\title{
Mechanical Ventilation in Children on Venovenous ECMO
}

\author{
Matthew L Friedman, Ryan P Barbaro, Melania M Bembea, Brian C Bridges, Ranjit S Chima, \\ Todd J Kilbaugh, Poornima Pandiyan, Renee M Potera, Elizabeth A Rosner, Hitesh S Sandhu, \\ James E Slaven, Keiko M Tarquinio, and Ira M Cheifetz
}

\begin{abstract}
BACKGROUND: Venovenous extracorporeal membrane oxygenation (VV-ECMO) is used when mechanical ventilation can no longer support oxygenation or ventilation, or if the risk of ventilator-induced lung injury is considered excessive. The optimum mechanical ventilation strategy once on ECMO is unknown. We sought to describe the practice of mechanical ventilation in children on VV-ECMO and to determine whether mechanical ventilation practices are associated with clinical outcomes. METHODS: We conducted a multicenter retrospective cohort study in 10 pediatric academic centers in the United States. Children age $14 \mathrm{~d}$ through $18 \mathrm{y}$ on VVECMO from 2011 to 2016 were included. Exclusion criteria were preexisting chronic respiratory failure, primary diagnosis of asthma, cyanotic heart disease, or ECMO as a bridge to lung transplant. RESULTS: Conventional mechanical ventilation was used in about $75 \%$ of children on VV-ECMO; the remaining subjects were managed with a variety of approaches. With the exception of PEEP, there was large variation in ventilator settings. Ventilator mode and pressure settings were not associated with survival. Mean ventilator $\mathrm{F}_{\mathrm{IO}_{2}}$ on days 1-3 was higher in nonsurvivors than in survivors $(0.5$ vs $0.4, P=.009)$. In univariate analysis, other risk factors for mortality were female gender, higher Pediatric Risk Estimate Score for Children Using Extracorporeal Respiratory Support (Ped-RESCUERS), diagnosis of cancer or stem cell transplant, and number of days intubated prior to initiation of ECMO (all $P<.05$ ). In multivariate analysis, ventilator $\mathrm{F}_{\mathrm{IO}_{2}}$ was significantly associated with mortality (odds ratio 1.38 for each 0.1 increase in $\mathrm{F}_{\mathrm{IO}_{2}}, 95 \%$ CI 1.09-1.75). Mortality was higher in subjects on high ventilator $\mathrm{F}_{\mathrm{IO}_{2}}$ $(\geq 0.5)$ compared to low ventilator $\mathrm{F}_{\mathrm{IO}_{2}}(>0.5)(46 \%$ vs $22 \%, P=.001)$. CONCLUSIONS: Ventilator mode and some settings vary in practice. The only ventilator setting associated with mortality was $\mathrm{F}_{\mathrm{IO}_{2}}$, even after adjustment for disease severity. Ventilator $\mathrm{F}_{\mathrm{IO}_{2}}$ is a modifiable setting that may contribute to mortality in children on VV-ECMO. Key words: artificial respiration; extracorporeal membrane oxygenation; pediatrics; acute respiratory distress syndrome; ventilatorinduced lung injury; oxygen. [Respir Care 2020;65(3):271-280. (C) 2020 Daedalus Enterprises]
\end{abstract}

\section{Introduction}

Pediatric ARDS is a common cause of morbidity and mortality in pediatric ICUs. ${ }^{1}$ Supportive care with mechanical ventilation using a lung-protective strategy is the

Dr Friedman is affiliated with the Division of Pediatric Critical Care, Riley Hospital for Children, Indiana University, Indianapolis, Indiana. Dr Barbaro is affiliated with the Department of Pediatrics, University of Michigan, Ann Arbor, Michigan. Dr Barbaro is affiliated with the Child Health Evaluation and Research Center, University of Michigan, Ann Arbor, Michigan. Dr Bembea is affiliated with the Department of Anesthesiology and Critical Care Medicine, Johns Hopkins University, cornerstone of treatment. ${ }^{2,3}$ However, there remains a population of patients with severe pediatric ARDS in whom mechanical ventilation cannot provide adequate gas exchange without inducing severe ventilator-induced lung injury. When initiated, venovenous extracorporeal membrane

Baltimore, Maryland. Dr Bridges is affiliated with the Division of Pediatric Critical Care, Department of Pediatrics, Vanderbilt University School of Medicine, Nashville, Tennessee. Dr Chima is affiliated with the Department of Pediatrics, University of Cincinnati College of Medicine, Cincinnati, Ohio. Dr Chima is affiliated with the Division of Critical Care Medicine, Cincinnati Children's Hospital Medical Center, Cincinnati, Ohio. Dr Kilbaugh is affiliated with the Department of 


\section{Mechanical Ventilation in Pediatric VV-ECMO}

oxygenation (VV-ECMO) relieves the lungs from their usual functions of oxygenation and ventilation, allowing for a reduction of high ventilator settings, which are associated with ventilator-induced lung injury. ${ }^{4,5}$

\section{See the Related Editorial on Page 400}

Mechanical ventilation strategies in adult and neonatal subjects with acute respiratory failure have been studied. ${ }^{6-14}$ Conversely, there has been little study of mechanical ventilation in children on ECMO support for respiratory failure, and there are no evidence-based or expert consensus guidelines. ${ }^{15,16}$ Ventilator management on ECMO has historically focused on a "lung rest" strategy to limit ventilator-induced lung injury. ${ }^{17-20}$ This approach typically consists of low ventilator rate, moderate PEEP, and low peak inspiratory pressure (PIP). The result is often complete lung collapse and limited native gas exchange. The scope of practice for mechanical ventilation in children on VV-ECMO has not been previously described in the literature, and it is unknown if there are any associations between ventilator practices and outcome. ${ }^{21}$

The primary aim of this study was to describe mechanical ventilation practice in pediatric subjects on VV-ECMO

\begin{abstract}
Anesthesiology and Critical Care Medicine, The Children's Hospital of Philadelphia, University of Pennsylvania School of Medicine, Philadelphia, Pennsylvania. Dr Pandiyan is affiliated with the Department of Pediatrics, University of Kansas School of MedicineWichita, Wichita, Kansas. Dr Potera is affiliated with the Department of Pediatrics UT Southwestern Medical Center, Dallas, Texas. Dr Rosner is affiliated with the Division of Pediatric Critical Care Medicine, Helen DeVos Children's Hospital, Grand Rapids, Michigan. Dr Sandhu is affiliated with the Division of Pediatric Critical Care, University of Tennessee Health Sciences Center, Memphis, Tennessee. Dr Slaven is affiliated with the Department of Biostatistics, Indiana University School of Medicine, Indianapolis, Indiana. Dr Tarquinio is affiliated with the Division of Pediatric Critical Care Medicine, Department of Pediatrics, Emory University, Children's Healthcare of Atlanta, Atlanta, Georgia. Dr Cheifetz is affiliated with the Division of Pediatric Critical Care, Duke Children's Hospital and Health Center, Durham, North Carolina.
\end{abstract}

Dr Friedman presented a version of this paper at the Extracorporeal Life Support Organization Annual Conference, held September 13-16, 2018, in Scottsdale, Arizona.

This study was supported financially by grants from the Extracorporeal Life Support Organization and the Pediatrics Department at Indiana University School of Medicine. Dr Barbaro discloses relationships with Extracorporeal Life Support Organization Registry and NHLBI, and the NIH. Dr Bembea discloses relationships with the NIH NICHD and NINDS. Dr Cheifetz discloses relationships with Philips, Up-to-Date, and the NHLBI. The remaining authors have disclosed no conflicts of interest.

Correspondence: Matthew L Friedman MD, Phase 2, Room 4900, 705 Riley Hospital Drive, Indianapolis, IN 46202. E-mail: friedmml@iu.edu.

DOI: $10.4187 /$ respcare. 07214

\section{QUICK LOOK}

\section{Current knowledge}

Extracorporeal membrane oxygenation allows for a reduction of ventilator settings to reduce the risk of ventilator-induced lung injury. There are no published reports of the management of mechanical ventilation in children on extracorporeal membrane oxygenation across multiple centers.

\section{What this paper contributes to our knowledge}

There was variability seen in ventilator mode and most settings, such as $\mathrm{F}_{\mathrm{IO}_{2}}$ and peak inspiratory pressure, with the exception of PEEP. The only ventilator setting associated with clinical outcomes was ventilator $\mathrm{F}_{\mathrm{IO}_{2}}$. After adjusting for severity of illness, every 0.1 increase in ventilator $\mathrm{F}_{\mathrm{IO}_{2}}$ was associated with a $38 \%$ increase in mortality.

for acute respiratory failure. The secondary aim was to evaluate whether any mechanical ventilation practices are associated with clinical outcomes.

\section{Methods}

A retrospective multi-center cohort study was conducted at 10 quaternary care pediatric academic centers in the United States with established ECMO programs: Riley Hospital for Children, Indianapolis, Indiana; John Hopkins Children's Center, Baltimore, Maryland; Vanderbilt Children's Hospital, Nashville, Tennessee; Cincinnati Children's Hospital, Cincinnati, Ohio; Children's Hospital of Philadelphia, Philadelphia, Pennsylvania; Children's Medical Center of Dallas, Dallas, Texas; Helen DeVos Children's Hospital, Grand Rapids, Michigan; Le Bonheur Children's Hospital, Memphis, Tennessee; Children's Hospital of Atlanta, Atlanta, Georgia; and Duke Children's Hospital and Health Center, Durham, North Carolina. Each center is a member of the Pediatric ECMO subgroup of the Pediatric Acute Lung Injury and Sepsis Investigators Network and the Extracorporeal Life Support Organization. Subjects were managed according to local protocols and clinician preferences. Institutional review board authorization was completed for all sites, either centrally at the lead institution (Indiana University) or locally. Need for informed consent was waived.

We reviewed the electronic medical records for children age $14 \mathrm{~d}$ through $18 \mathrm{y}$ who were cannulated for VV-ECMO from 2011 to 2016. Exclusion criteria were ECMO as a bridge to lung transplant, asthmas as the primary cause of acute respiratory failure, cyanotic congenital heart disease (ie, unrepaired cyanotic congenital heart disease or single- 


\section{Mechanical Ventilation in Pediatric VV-ECMO}

ventricle physiology), or preexisting chronic respiratory failure (defined as ventilator dependence, positive-pressure ventilation, or home $\mathrm{O}_{2}$ not for obstructive sleep apnea). Data for subjects who were converted to venoarterial ECMO were included in the descriptive analysis, but these subjects were excluded from further analyses of outcome measures.

Data collection was completed via a HIPAA-compliant online data entry web site (REDCap, Vanderbilt University, Nashville, Tennessee). Pre-ECMO data collected included demographics, Pediatric Pulmonary Rescue With Extracorporeal Membrane Oxygenation Prediction variables, ${ }^{22}$ and Pediatric Risk Estimate Score for Children Using Extracorporeal Respiratory Support (Ped-RESCUERS) variables. ${ }^{23}$ Ventilator mode and settings, blood gas values, and ECMO settings were recorded for the first $7 \mathrm{~d}$ on ECMO, using values recorded closest to $8 \mathrm{AM}$. The preECMO ventilator settings were the settings documented closest to the 8 AM before cannulation. The average for the first $3 \mathrm{~d}$ on ECMO were used for analysis based on previous literature. ${ }^{7,9}$ Subjects were dichotomized based on average oxygen saturation measured via pulse oximetry $\left(\mathrm{S}_{\mathrm{pO}_{2}}\right)$ and average $\mathrm{F}_{\mathrm{IO}_{2}}$ over the first $3 \mathrm{~d}$ on ECMO, and cutoffs were determined with sensitivity analysis and Youden's J statistic.

\section{Definitions}

Survival was defined as survival to ICU discharge. Cardiac arrest was defined as cessation of a perfusing rhythm requiring cardiopulmonary resuscitation for $>2$ min. Driving pressure was estimated as the difference between PEEP and PIP. Plateau pressure was only available for a small number of subjects because most subjects on conventional mechanical ventilation were on a pressure mode of ventilation with variable inspiratory flow. Composite outcomes of ECMO-free days and alive days at $28 \mathrm{~d}$ and ventilator-free and alive days at $90 \mathrm{~d}$ were determined. ECMO-free days was considered zero for subjects who did not survive ECMO. ECMO-free days for subjects who survived ECMO were calculated by subtracting duration of ECMO from $28 \mathrm{~d}$; if ECMO duration was $>28$ d, ECMO-free days was considered zero. Ventilator-free days was considered zero for any subjects who did not survive to extubation or received tracheostomy. Ventilatorfree days for other subjects was calculated by subtracting the length of ventilation from $90 \mathrm{~d}$; if subjects were ventilated for $>90 \mathrm{~d}$, ventilator-free days was considered zero. The predominant mode of ventilation was the most frequently used mode within the first $7 \mathrm{~d}$ on ECMO. In the case of a tie, the most frequent mode in the first $3 \mathrm{~d}$ was used. Acute kidney failure was diagnosed if the subject met criteria based on Kidney Disease Improving Global
Outcomes or pediatric risk, injury, failure, loss, and endstage renal disease criteria. ${ }^{24,25}$

\section{Statistical Analysis}

Variables of interest were analyzed to compare survivors and nonsurvivors. Distributions of the variables are presented as median (interquartile range). Bivariate associations between survivor groups were assessed with Wilcoxon nonparametric tests. Multivariate logistic regression and Cox proportional hazard models were performed, with survival as the outcome variable and center variability accounted for with a random intercept, also called a mixed-effects logistic regression or hierarchical regression. Variables associated with mortality in bivariate analysis were included in the multivariate analyses, with the exception of variables that were part of the composite mortality risk score (ie, Ped-RESCUERS). Multivariate logistic regression was used for the primary multivariate analysis. The Cox proportional hazard model was used for the analysis with $\mathrm{F}_{\mathrm{IO}_{2}}, \mathrm{~S}_{\mathrm{pO}_{2}}$, gender, and Ped-RESCUERS score. Generalized linear models were used to incorporate a random effect for hospital to account for within-hospital correlation. Variables for inclusion in the multivariate model were chosen on the basis of bivariate analyses, where $P<$ .05. Days from intubation to ECMO and diagnosis of cancer had $P<.05$ but are included in the Ped-RESCUERS score, a composite mortality risk score for pediatric respiratory ECMO, and were therefore not included. ${ }^{23}$ Correlation analyses were performed using Spearman nonparametric correlation analyses, both for general analyses and to inform for any collinearity issues with the multivariate models. Chi-square analyses were performed to evaluate for significant heterogeneity between categorical variables. All analyses were performed using SAS 9.4 (SAS Institute, Cary, North Carolina).

\section{Results}

\section{Cohort Characteristics}

After applying exclusion criteria, 204 subjects were included in the cohort, with 6-50 subjects contributed per center. Four higher-volume centers had 28-50 subjects, and the 6 lower-volume centers had 6-14 subjects. The median age was 3.6 y with $53 \%$ female subjects. There were 24 patients that were transitioned form V-V ECMO to veno-arterial ECMO, they were included in descriptive analysis but excluded from univariate and multivariate analysis. The etiologies of respiratory failure were viral infection other than respiratory syncytial virus (29\%), other causes (28\%), respiratory syncytial virus infection $(17 \%)$, bacterial pneumonia (13\%), aspiration (6\%), sepsis (4\%), fungal pneumonia $(2 \%)$, and pertussis $(1 \%)$. The median pre-ECMO 
Table 1. Demographics and Pre-ECMO Characteristics

\begin{tabular}{|c|c|c|c|}
\hline Variable & Survivors & Nonsurvivors & $P$ \\
\hline Age, y & $3.6(1.1-12.1)$ & $3.4(0.6-13.5)$ & .83 \\
\hline Female & $61(48)$ & $35(66)$ & .03 \\
\hline Weight, kg & $15.9(9.0-50.0)$ & $15.3(8.0-52.3)$ & .69 \\
\hline Pre-ECMO cardiac arrest & $16(13)$ & $3(6)$ & .16 \\
\hline Cancer or stem cell transplant & $10(8)$ & $13(25)$ & .002 \\
\hline Chronic lung disease & $10(8)$ & $1(2)$ & .18 \\
\hline Prematurity & $30(24)$ & $10(19)$ & .48 \\
\hline Genetic disorder & $12(9)$ & $5(9)$ & .99 \\
\hline Pre-ECMO duration of ventilation, $\mathrm{d}$ & $2(0-5)$ & $4(1-8)$ & .02 \\
\hline \multicolumn{3}{|l|}{ Pre-ECMO mode of ventilation } & .58 \\
\hline Conventional mechanical ventilation & $34(27)$ & $17(32)$ & NA \\
\hline Airway pressure release ventilation & $11(9)$ & $5(9)$ & NA \\
\hline High-frequency oscillatory ventilation & $76(60)$ & $28(53)$ & NA \\
\hline Other & $6(5)$ & $3(6)$ & NA \\
\hline Ped-RESCUERS score & $-0.6(-1.2$ to -0.1$)$ & $-0.2(-0.7$ to 0.2$)$ & .001 \\
\hline PPREP score & $3.0(0.0-4.0)$ & $4.0(2.0-10.0)$ & .001 \\
\hline $\mathrm{P}_{\mathrm{aO}_{2}} / \mathrm{F}_{\mathrm{IO}_{2}}$ & $61(46-101)$ & $66(45-90)$ & .82 \\
\hline Oxygenation index & $47(33-62)$ & $49(36-64)$ & .60 \\
\hline \multicolumn{4}{|c|}{$\begin{array}{l}\text { Data are presented as median (interquartile range) for continuous variables and } n(\%) \text { for categorical varia } \\
\text { exact tests, respectively. } \\
\text { ECMO = extracorporeal membrane oxygenation } \\
\text { Ped-RESCUERS = Pediatric Risk Estimate Score for Children Using Extracorporeal Respiratory Support } \\
\text { PPREP = Pediatric Pulmonary Rescue With Extracorporeal Membrane Oxygenation Prediction } \\
\text { NA = not applicable }\end{array}$} \\
\hline
\end{tabular}

oxygenation index was 47 (IQR 35-62). Overall survival was $68 \%$. The most common causes of death were multiorgan failure $(30 \%)$, bleeding complication $(30 \%)$, and refractory lung disease $(25 \%)$. The median duration of ECMO was $190 \mathrm{~h}$ (IQR 117-337). Tracheostomy was placed after ECMO in 22 subjects (11\%), and 14 subjects (7\%) were discharged on home mechanical ventilation.

Select demographic and pre-ECMO variables are presented in Table 1. Female gender $(P=.03)$, cancer diagnosis or stem cell transplant $(P=.002)$, pre-ECMO duration of ventilation $(P=.02)$, and mortality risk score $(P=.001)$ differed between survivors and nonsurvivors.

\section{Description of Mechanical Ventilation and Pulmonary Management on ECMO}

Traditional ventilator modes were used on most subject days $(73.4 \%)$. Among the subjects on conventional modes, pressure-targeted modes were the most common $(90.3 \%)$, followed by pressure-regulated volume control $(8.7 \%)$ and volume-targeted modes $(1 \%)$. A minority of subjects $(9 \%)$ were ventilated with assist control modes. Nonconventional modes of ventilation were used in about a quarter of subjects on each day of ECMO. Airway pressure release ventilation was the most common nonconventional mode (13.4\%). The frequency of ventilator mode and median ventilator settings pre-ECMO and on ECMO days 1,3 , and 5 are presented in Table 2. Prior to ECMO cannulation, $\mathrm{F}_{\mathrm{IO}_{2}}$ was $\geq 0.5$ in $98 \%$ of subjects, and $43 \%$ of subjects remained on high $\mathrm{F}_{\mathrm{IO}_{2}}$ (defined as $\mathrm{F}_{\mathrm{IO}_{2}} \geq 0.5$ ) on day 1 of ECMO, whereas that number decreased to $24 \%$ by day 3 of ECMO. Ventilator settings pre-ECMO and on ECMO days 1, 3, and 5 are also displayed in Figure 1. Surfactant was administered to 6 subjects; 3 subjects received a second dose, and one 12-month-old with aspiration received 3 doses. Prone positioning was used for 3 subjects, each for only $1 \mathrm{~d}$.

\section{Outcomes Analysis}

After excluding subjects converted to venoarterial ECMO and the 1 subject transferred on ECMO, 180 subjects were including in the bivariate and multivariate analyses. Ventilator mode, pressure settings, and other ventilator measurements were similar in survivors and nonsurvivors (Table 3). Ventilator $\mathrm{F}_{\mathrm{IO}_{2}}$ was higher in nonsurvivors compared to survivors at 0.5 (IQR 25 th\%-75th\%) versus 0.4 (IQR 0.3-0.5) $(P=.009)$. ECMO circuit settings did not differ between survivors and nonsurvivors.

Mode of ventilation on ECMO was not associated with ECMO-free days or ventilator-free days. No ventilator pressure setting or measurement was associated with ECMOfree days or ventilator-free days. Ventilator $\mathrm{F}_{\mathrm{IO}_{2}}$ was associated with ECMO-free days (Spearman correlation coefficient $-0.173, P=.02$ ) and ventilator-free days (Spearman correlation coefficient $-0.223, P=.003$ ). 
Table 2. Mechanical Ventilation Settings Pre-ECMO and on ECMO Days 1, 3, and 5

\begin{tabular}{|c|c|c|c|c|}
\hline Variable & Pre-ECMO & Day 1 & Day 3 & Day 5 \\
\hline \multicolumn{5}{|l|}{ Mode } \\
\hline Conventional mechanical ventilation & $54(27)$ & $149(74)$ & $137(74)$ & $116(73)$ \\
\hline High-frequency oscillatory ventilation & $123(61)$ & $21(11)$ & $9(5)$ & $9(6)$ \\
\hline Airway pressure release ventilation & $16(8)$ & $23(11)$ & $28(15)$ & $21(13)$ \\
\hline High-frequency percussive ventilation & $1(0.5)$ & $5(3)$ & $7(4)$ & $7(4)$ \\
\hline Extubated & $0(0)$ & $0(0)$ & $2(1)$ & $4(3)$ \\
\hline Other & $9(4)$ & $3(2)$ & $2(1)$ & $2(1)$ \\
\hline$\overline{\mathrm{P}}_{\mathrm{aw}}$, all modes, $\mathrm{cm} \mathrm{H}_{2} \mathrm{O}$ & $28(20-30)$ & $14(12-18)$ & $14(13-17)$ & $15(12-18)$ \\
\hline $\mathrm{F}_{\mathrm{IO}_{2}}$, all modes & $1.0(0.9-1.0)$ & $0.4(0.3-0.6)$ & $0.4(0.3-0.45)$ & $0.4(0.3-0.5)$ \\
\hline $\mathrm{F}_{\mathrm{IO}_{2}} \geq 0.5$ & $187(98)$ & $85(43)$ & $43(24)$ & $45(29)$ \\
\hline \multicolumn{5}{|l|}{ Conventional mechanical ventilation } \\
\hline Breathing frequency, breaths/min & $24(20-33)$ & $10(10-12)$ & $10(10-10)$ & $10(10-15)$ \\
\hline $\mathrm{F}_{\mathrm{IO}_{2}}$ & $1.0(0.7-1.0)$ & $0.4(0.3-0.6)$ & $0.3(0.3-0.4)$ & $0.4(0.3-0.5)$ \\
\hline $\mathrm{PEEP}, \mathrm{cm} \mathrm{H}_{2} \mathrm{O}$ & $10(8-12)$ & $10(10-10)$ & $10(10-10)$ & $10(10-10)$ \\
\hline$\overline{\mathrm{P}}_{\mathrm{aw}}, \mathrm{cm} \mathrm{H}_{2} \mathrm{O}$ & $18(15-24)$ & $13(12-15)$ & $13(12-15)$ & $13(12-15)$ \\
\hline $\mathrm{PIP}, \mathrm{cm} \mathrm{H}_{2} \mathrm{O}$ & $32(28-38)$ & $20(20-25)$ & $20(20-25)$ & $20(20-25)$ \\
\hline Driving pressure, $\mathrm{cm} \mathrm{H}_{2} \mathrm{O}$ & $31(22-37)$ & $10(10-15)$ & $10(10-14)$ & $10(10-15)$ \\
\hline Compliance, $\mathrm{mL} / \mathrm{cm} \mathrm{H}_{2} \mathrm{O}$ & $4.8(2.1-9.5)$ & $1.9(0.6-4.9)$ & $1.8(0.9-4.9)$ & $2.0(1.0-6.5)$ \\
\hline Tidal volume, $\mathrm{mL} / \mathrm{kg}$ & $6.0(4.5-6.9)$ & $1.9(0.7-3.5)$ & $1.9(0.7-4.0)$ & $2.3(1.0-5.2)$ \\
\hline $\mathrm{T}_{\mathrm{I}}, \mathrm{s}$ & $0.9(0.7-1.0)$ & $1.0(0.9-2.0)$ & $1.1(1.0-2.0)$ & $1.0(0.9-2.0)$ \\
\hline \multicolumn{5}{|l|}{ High-frequency oscillatory ventilation } \\
\hline$\overline{\mathrm{P}}_{\mathrm{aw}}, \mathrm{cm} \mathrm{H}_{2} \mathrm{O}$ & $30(26-32)$ & $24(16-29)$ & $18(14-24)$ & $25(17-27)$ \\
\hline Frequency, Hz & $7(6-8)$ & $7(6-8)$ & $6(5-8)$ & $8(6-10)$ \\
\hline $\mathrm{F}_{\mathrm{IO}_{2}}$ & $1.0(0.9-1.0)$ & $0.6(0.4-0.7)$ & $0.5(0.4-0.5)$ & $0.4(0.4-0.5)$ \\
\hline Amplitude & $60(50-75)$ & $42(34-72)$ & $40(28-50)$ & $40(30-52)$ \\
\hline \multicolumn{5}{|l|}{ Airway pressure release ventilation } \\
\hline $\mathrm{F}_{\mathrm{IO}_{2}}$ & $1.0(0.9-1.0)$ & $0.5(0.4-0.6)$ & $0.4(0.4-0.5)$ & $0.4(0.4-0.5)$ \\
\hline$\overline{\mathrm{P}}_{\mathrm{aw}}, \mathrm{cm} \mathrm{H}_{2} \mathrm{O}$ & $27(23-28)$ & $19(18-26)$ & $19(19-22)$ & $21(19-23)$ \\
\hline $\mathrm{T}_{\text {high }}, \mathrm{s}$ & $4(2-5)$ & $5(4-6)$ & $5(4-6)$ & $5(4-6)$ \\
\hline $\mathrm{T}_{\text {low }}, \mathrm{s}$ & $0.3(0.3-0.5)$ & $0.3(0.3-0.4)$ & $0.3(0.3-0.4)$ & $0.3(0.3-0.4)$ \\
\hline $\mathrm{P}_{\text {high }}, \mathrm{cm} \mathrm{H}_{2} \mathrm{O}$ & $30(26-32)$ & $20(20-28)$ & $20(20-24)$ & $24(20-26)$ \\
\hline $\mathrm{P}_{\text {low }}, \mathrm{cm} \mathrm{H} \mathrm{H}_{2} \mathrm{O}$ & $0(0-0)$ & $0(0-1)$ & $0(0-3)$ & $0(0-2)$ \\
\hline \multicolumn{5}{|l|}{ High-frequency percussive ventilation } \\
\hline $\mathrm{M}_{\mathrm{awp}}, \mathrm{cm} \mathrm{H} \mathrm{H}_{2} \mathrm{O}$ & NA & $21(21-24)$ & $20(16-22)$ & $20(17-21)$ \\
\hline Pulsate flow, pulses/min & NA & $550(550-600)$ & $550(500-600)$ & $600(550-600)$ \\
\hline Breathing frequency, breaths/min & NA & $15(10-20)$ & $20(10-24)$ & $19(17-22)$ \\
\hline $\mathrm{F}_{\mathrm{IO}_{2}}$ & NA & $0.3(0.2-0.3)$ & $0.4(0.3-0.4)$ & $0.4(0.4-0.5)$ \\
\hline Oscillatory CPAP, $\mathrm{cm} \mathrm{H}_{2} \mathrm{O}$ & NA & $6.5(4.0-7.8)$ & $5.9(3.5-8.5)$ & $6(4-9)$ \\
\hline $\begin{array}{l}\text { Data are presented as median (interquartile range) for c } \\
\text { ECMO = extracorporeal membrane oxygenation } \\
\text { NA = not applicable } \\
\bar{P}_{\text {aw }}=\text { mean airway pressure } \\
P I P=\text { peak inspiratory pressure } \\
T \text { = time } \\
P=\text { pressure } \\
M_{\text {awp }}=\text { maximum allowable working pressure }\end{array}$ & bles and $n(\%)$ for ca & & & \\
\hline
\end{tabular}

Multivariate analysis for mortality included female gender, Ped-RESCUERS score, and mean $\mathrm{F}_{\mathrm{IO}_{2}}$ over the first 3 d on ECMO (Table 4). In multivariate analysis, ventilator $\mathrm{F}_{\mathrm{IO}_{2}}$ was significantly associated with mortality (odds ratio 1.38 for each 0.1 increase in $\mathrm{F}_{\mathrm{IO}_{2}}, 95 \%$ CI 1.09-1.75).

Mortality was higher in subjects on high ventilator $\mathrm{F}_{\mathrm{IO}_{2}}(\geq 0.50)$ compared to low $\mathrm{F}_{\mathrm{IO}_{2}}$ (46\% vs $22 \%, P=$ $.001)$. Mortality was higher for children with low $\mathrm{S}_{\mathrm{pO}_{2}}$
( $\leq 85 \%)$ compared to high $\mathrm{S}_{\mathrm{pO}_{2}}$ (46\% vs $30 \%, P=.02$ ). The hazard ratio (HR) for mortality in the high $\mathrm{F}_{\mathrm{IO}_{2}}$ group was 2.1 (95\% CI 1.05-4.20) with adjustment for high $\mathrm{S}_{\mathrm{pO}_{2}}$ (HR 0.9, 95\% CI 0.4-1.9), female gender (HR 1.5, 95\% CI 0.8-2.9), and Ped-RESCUERS (HR 1.2, 95\% CI 0.7-2.1).

A scatter plot of the $\mathrm{S}_{\mathrm{pO}_{2}}$ and ventilator $\mathrm{F}_{\mathrm{IO}_{2}}$ on ECMO is presented in Figure 2. The points were divided into quadrants based on high or low $\mathrm{S}_{\mathrm{pO}_{2}}$ and high or low 

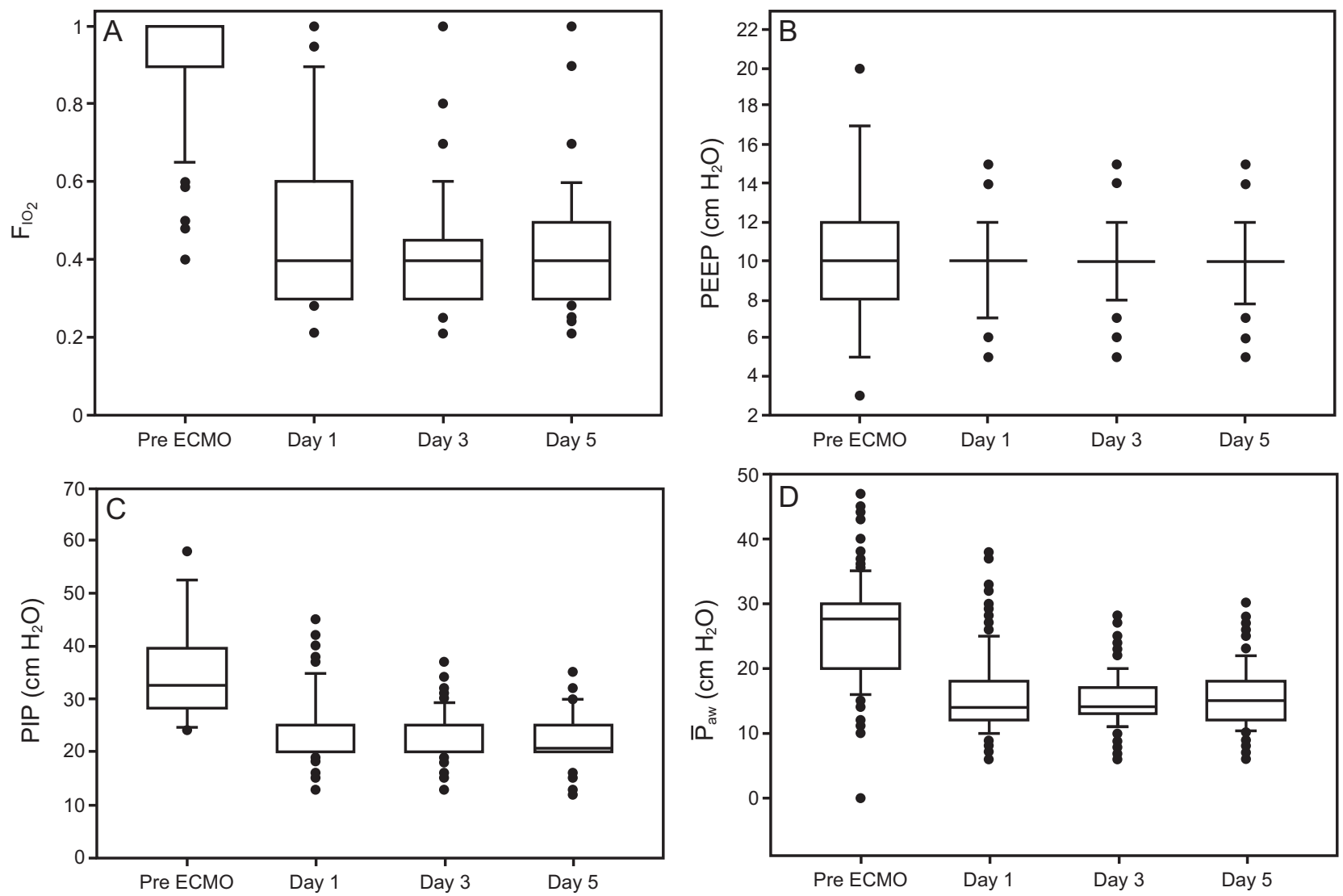

Fig. 1. Ventilator settings pre-ECMO and on ECMO days 1, 3, and 5. ECMO = extracorporeal membrane oxygenation; PIP = peak inspiratory pressure; $\bar{P}_{\text {aw }}=$ mean airway pressure. Boxes represent 25th to 75th percentile values, with median shown as a horizontal line within each box. Whiskers denote 5 th to 95 th percentiles, and points represent outliers.

$\mathrm{F}_{\mathrm{IO}_{2}}$. Survival differed significantly based on quadrant $(P=.002)$.

\section{Complications}

Conversion to venoarterial ECMO was performed in 23 subjects (11\%). Subjects converted to venoarterial ECMO had lower survival (44\% vs $71 \%, P=.009$ ). Subjects requiring conversion to venoarterial ECMO were older (3.6 vs $1.4 \mathrm{y}, P=.005)$, had a higher maximum heart rate (174 vs 159 beats/min, $P=.009$ ), and were more likely to have an oncological diagnosis or hematopoietic cell transplant (30\% vs $13 \%, P=.03$ ). There were 27 pneumothoraces in the first $7 \mathrm{~d}$ on ECMO, for an incidence of $2.3 \%$ per day. Ventilator settings on the day of or the day before were not associated with pneumothorax. Tracheostomy was performed in 22 subjects, all after ECMO, and 14 subjects were discharged on mechanical ventilation.

\section{Discussion}

There have been many improvements in the care for children on ECMO; however, the contribution of mechanical ventilation management to morbidity and mortality has not been evaluated. ${ }^{26}$ This study represents the first multi-center study of mechanical ventilation in pediatric subjects on ECMO. We noted variability in ventilator mode and settings for children on VV-ECMO ${ }^{26}$ In this study, neither mode of ventilation nor ventilator pressure parameters were associated with survival. Ventilator $\mathrm{F}_{\mathrm{IO}_{2}}$, however, was associated with mortality, even after adjustment for severity of illness.

The majority of subjects were ventilated with conventional modes of ventilation; approximately $25 \%$ of subjects were on other modes of ventilation each day. We noted higher use of nonconventional modes during ECMO than reported previously, although most adult studies of mechanical ventilation on ECMO have used conventional mechanical ventilation exclusively, with a few recent studies reporting small number of subjects on airway pressure release ventilation. ${ }^{6-11,17,27}$ Neonates on ECMO predominantly receive conventional mechanical ventilation $(88 \%) .{ }^{11}$ There was variability in some ventilator settings, including $\mathrm{F}_{\mathrm{IO}_{2}}$ and mean airway pressure $\left(\overline{\mathrm{P}}_{\mathrm{aw}}\right)$. The median values of $\mathrm{F}_{\mathrm{IO}_{2}}$ and $\overline{\mathrm{P}}_{\mathrm{aw}}$ in our study were lower than reported in adult studies, but the 


\section{Mechanical Ventilation in Pediatric VV-ECMO}

Table 3. Ventilator and ECMO Characteristics

\begin{tabular}{lcc}
\hline \hline \multicolumn{1}{c}{ Variable } & Survivors & Nonsurvivors \\
\hline Predominant mode of ventilation on ECMO & & $P$ \\
$\quad$ Conventional mechanical ventilation & $96(76)$ & $40(76)$ \\
$\quad$ High-frequency oscillatory ventilation & $4(3)$ & $4(8)$ \\
$\quad$ Aiway pressure release ventilation & $19(15)$ & $6(11)$ \\
$\quad$ High-frequency percussive ventilation & $7(6)$ & $1(2)$ \\
$\quad$ Extubated & $1(1)$ & $2(4)$ \\
$\mathrm{PEEP}, \mathrm{cm} \mathrm{H}_{2} \mathrm{O}$ & $10(10-10)$ & $10(10-10)$ \\
$\overline{\mathrm{P}}_{\mathrm{aw}}, \mathrm{cm} \mathrm{H}_{2} \mathrm{O}$ & $14.7(13.0-17.7)$ & $14.2(12.5-16.7)$ \\
Driving pressure, cm $\mathrm{H}_{2} \mathrm{O}$ & $11(10-16)$ & $11.3(10-15)$ \\
Ventilator $\mathrm{F}_{\mathrm{IO}}$ & $0.4(0.3-0.5)$ & $0.5(0.3-0.6)$ \\
$\mathrm{Tidal}$ volume, $\mathrm{mL} / \mathrm{kg}$ & $2.5(0.9-4.4)$ & $1.7(1.1-2.7)$ \\
$\mathrm{S}_{\mathrm{pO}}$ & $92(88-94)$ & $91(85-93)$ \\
$\mathrm{P}_{\mathrm{aCO}}$ & $45.6(42.3-49.2)$ & $46.1(42.0-53.0)$ \\
$\mathrm{ECMO}$ circuit flow, $\mathrm{mL} / \mathrm{kg}$ & $81(56-97)$ & $87(54-99)$ \\
$\mathrm{ECMO}$ circuit sweep, $\mathrm{L} /$ min & $2.1(1.0-5.0)$ & $3.6(1.0-5.6)$ \\
$\mathrm{Circuit} \mathrm{F}_{\mathrm{s}} \mathrm{O}_{2}$ & $0.9(0.7-1.0)$ & $1.0(0.9-1.0)$ \\
\hline Data are presented as median (interquartile range) for continuous variables and $n(\%)$ for categorical variables. $n=127$ survivors; $n=53$ nonsurvivors. $P$ values are from Wilcoxon rank-sum and Fisher \\
exact tests, respectively.
\end{tabular}

Table 4. Multivariate Model for Mortality

\begin{tabular}{lcc}
\hline \hline \multicolumn{1}{c}{ Variable } & Adjusted Odds Ratio (95\% CI) & $P$ \\
\hline Female & $2.04(0.99-4.21)$ & .053 \\
Ped-RESCUERS score & $2.11(1.19-3.73)$ & .01 \\
3-d ventilator $\mathrm{F}_{\mathrm{IO}_{2}}$ average & $1.38^{*}(1.09-1.75)$ & .008 \\
& & \\
* per 0.1 change in ventilator $\mathrm{F}_{\mathrm{IO}_{2}}$. & & \\
Ped-RESCUERS = Pediatric Risk Estimate Score for Children Using Extracorporeal Respiratory \\
Support
\end{tabular}

variability was similar. $^{7-9}$ Conversely, PEEP and PIP showed very little variability in our cohort. The median and interquartile values for PEEP on ECMO were all $10 \mathrm{~cm} \mathrm{H}_{2} \mathrm{O}$. Adult and neonatal studies have reported wider variability in PEEP than observed in our study, with adults tending to be supported on higher PEEP and neonates on lower PEEP. ${ }^{6-11}$ Most subjects in the study had a PIP of $20 \mathrm{~cm} \mathrm{H}_{2} \mathrm{O}$, which was the median and 25th percentile values on ECMO day 1 and day 3 . The PIP used in children in this study is lower than what has been used in most adult studies. ${ }^{6,8,9}$

Surveys on the practice of mechanical ventilation on ECMO have reported increasing use of an open-lung ventilation strategy on ECMO. ${ }^{20,28}$ Open-lung ventilation is accomplished with high PEEP on conventional mechanical ventilation or with high $\overline{\mathrm{P}}_{\mathrm{aw}}$-targeted modes of ventilation, such as airway pressure release ventilation or high-frequency oscillatory ventilation. The existing data to support this approach in adults are inconsistent. High-PEEP strategies in adult studies have reported divergent outcomes. $^{6-9,29}$ Higher PEEP in neonates leads to shorter ECMO duration and fewer complications. ${ }^{11,30}$ However, low PEEP was defined as 4-6 $\mathrm{cm} \mathrm{H}_{2} \mathrm{O}$. PEEP this low was rarely seen in our study and is not commonly used in pediatric ECMO. We did not observe any associations between clinical outcomes and PEEP, $\overline{\mathrm{P}}_{\mathrm{aw}}$, or high $\overline{\mathrm{P}}_{\mathrm{aw}}$-targeted modes; therefore, our data do not support an open-lung strategy on ECMO over traditional rest settings.

Neither estimated driving pressure nor PIP were associated with clinical outcomes in this study, which was a surprising outcome because adult studies have previously reported higher driving pressure to be associated with mortality. ${ }^{6,8,9}$ The estimated driving pressures observed in our study are lower than those in adult studies, and the detrimental effect of driving pressure is not seen at lower levels, which may explain the difference in results. ${ }^{8,9}$ Additionally, it is not clear that low tidal-volume ventilation in ARDS is as beneficial in children as it is in adults. ${ }^{31,32}$

No ventilator pressure settings were associated with the outcomes measured, although most subjects were on settings that would be considered lung-protective. This is consistent with recent reports that markers of biotrauma to the lungs decrease after ECMO initiation and the reduction of ventilator settings, but there were no differences between various ventilator approaches on ECMO. ${ }^{33}$ Because there is variability between patients regarding lung disease severity and potential for recruitment, an individualized approach to ventilator management while avoiding potentially injurious settings seems reasonable. ${ }^{34}$ 


\section{Mechanical Ventilation in Pediatric VV-ECMO}

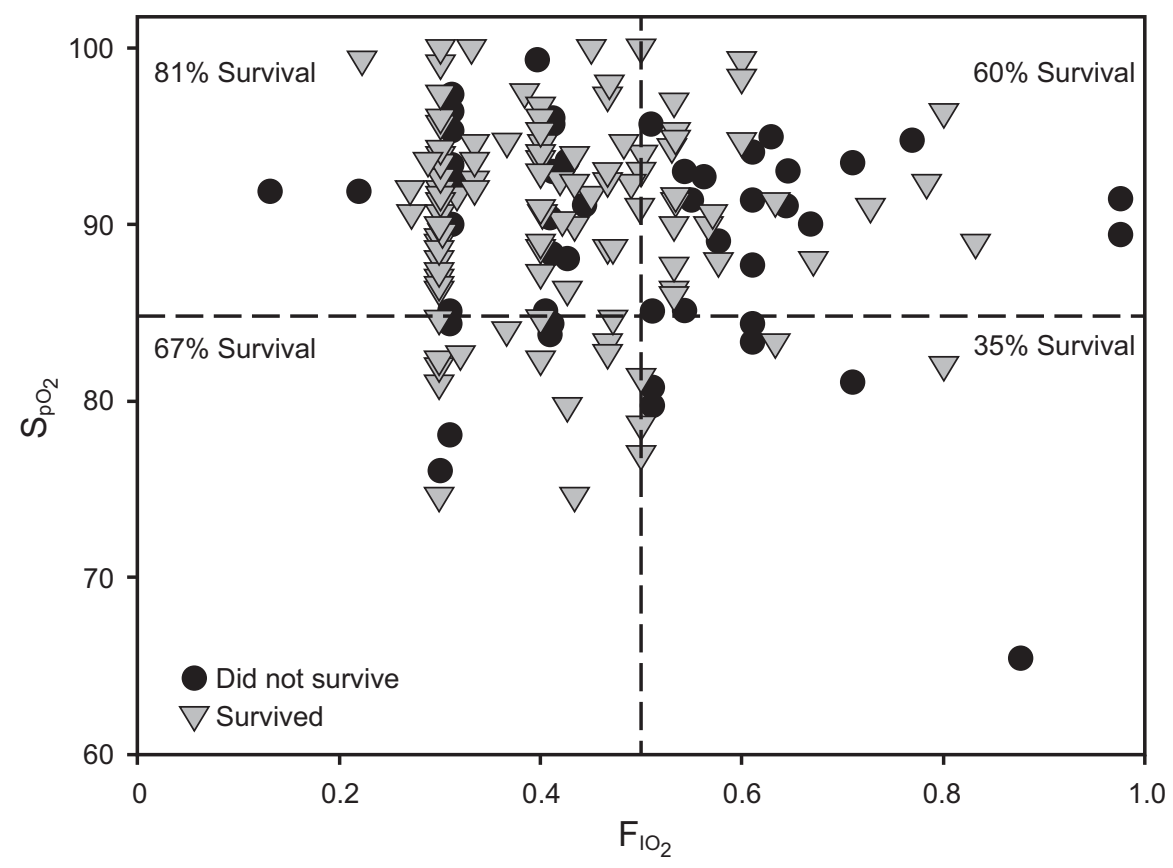

Fig. 2. Scatter plot of $\mathrm{S}_{\mathrm{pO}_{2}}$ and ventilator $\mathrm{F}_{1 \mathrm{I}_{2}}$ on extracorporeal membrane oxygenation. Subjects are divided into quadrants based on $\mathrm{F}_{1 \mathrm{O}_{2}} \geq$ 0.5 vs $<0.5$ and $\mathrm{S}_{\mathrm{pO}_{2}}$ and ventilator $\mathrm{F}_{\mathrm{IO}_{2}}>85 \%$ vs $\leq 85 \%$. ICU survival for subjects in each quadrant is displayed. Survival differed across the four quadrants $(P=.002)$.

Ventilator $\mathrm{F}_{\mathrm{IO}_{2}}$ was also the only ventilator setting that was associated with mortality. In multivariate analysis, with adjustment for severity of illness, for every 0.1 increase in $\mathrm{F}_{\mathrm{IO}_{2}}$ there was a $38 \%$ increased odds of mortality. Most studies of ventilation on ECMO do not report ventilator $\mathrm{F}_{\mathrm{IO}_{2}}$; one study reported that ventilator $\mathrm{F}_{\mathrm{IO}_{2}}$ was associated with mortality in univariate analysis but not in multivariate analysis, ${ }^{8}$ whereas another study noted no relationship. ${ }^{6}$

Oxygen supplementation is very common in the modern ICU, although it has become increasingly evident that the benefits of oxygen therapy must be weighed against the toxicities. ${ }^{35}$ High oxygen tension leads to the creation of reactive oxygen species that cause inflammation, edema, damage to cellular components, and cell death. ${ }^{36,37}$ In air with high $\mathrm{F}_{\mathrm{IO}_{2}}$, nitrogen is replaced by oxygen, which washes out nitrogen from alveoli. Oxygen is then readily absorbed into the lung tissues, leading to alveolar collapse, absorptive atelectasis, and increased intrapulmonary shunting. ${ }^{38-40}$ High $\mathrm{F}_{\mathrm{IO}_{2}}$ contributes to ventilator-induced lung injury through the production of reactive oxygen species and atelectrauma. ${ }^{4,5}$

The association between ventilator $\mathrm{F}_{\mathrm{IO}_{2}}$ and mortality observed in our study may be due to the direct toxic effects of $\mathrm{F}_{\mathrm{IO}_{2}}$. However, there are potential confounders that could drive this association, such as severity of disease or inadequacy of ECMO support. The multivariate models included adjustment for pre-ECMO severity of disease (Ped-RESCUERS score), and ventilator $\mathrm{F}_{\mathrm{IO}_{2}}$ remained associated with mortality. Measures of ECMO support, including circuit flow, circuit sweep, and circuit sweep gas inlet oxygen fraction $\left(\mathrm{F}_{\mathrm{s}} \mathrm{O}_{2}\right)$ did not differ between survivors and nonsurvivors, which suggests a similar degree of ECMO support. Children on VVECMO with severe lung injury and inadequate ECMO support have lower $\mathrm{S}_{\mathrm{pO}_{2}}$ and may be preferentially placed on high ventilator $\mathrm{FIO}_{2}$. The severity of illness and lack of adequate ECMO support could be driving the observed association between mortality and high $\mathrm{F}_{\mathrm{IO}_{2}} \cdot \mathrm{S}_{\mathrm{pO}_{2}}$ was not associated with mortality when analyzed as a continuous variable; in the Cox proportional hazard model that included $\mathrm{S}_{\mathrm{pO}_{2}}$ (high vs low), $\mathrm{F}_{\mathrm{IO}_{2}}$ (high vs low), and severity of illness, low $\mathrm{S}_{\mathrm{pO}_{2}}$ was not associated with mortality. Conversely, high $\mathrm{F}_{\mathrm{IO}_{2}}$ predicted a 2.1 times higher risk of death. Therefore, the link between ventilator $\mathrm{F}_{\mathrm{IO}_{2}}$ and mortality is not likely due to severe lung injury and inadequate ECMO support.

Ventilator $\mathrm{F}_{\mathrm{IO}_{2}}$ is used to increase $\mathrm{S}_{\mathrm{pO}_{2}}$ and ultimately to increase systemic oxygen delivery. However, the clinical dilemma is how to weigh the risks of high ventilator $\mathrm{F}_{\mathrm{IO}_{2}}$ against the risks of low $\mathrm{S}_{\mathrm{pO}_{2}}$. The balance between $\mathrm{S}_{\mathrm{pO}_{2}}$ and $\mathrm{F}_{\mathrm{IO}_{2}}$ was explored with a scatter plot (Fig. 2). Subjects on high $\mathrm{F}_{\mathrm{IO}_{2}}$ with high $\mathrm{S}_{\mathrm{pO}_{2}}$ (upper right quadrant), and those on low $\mathrm{F}_{\mathrm{IO}_{2}}$ with low $\mathrm{S}_{\mathrm{pO}_{2}}$ (lower left quadrant) are most interesting to compare. Hypothetically some patients may be able to move between these 2 quadrants by titrating ventilator $\mathrm{F}_{\mathrm{IO}_{2}}$, resulting in a corresponding change in $\mathrm{S}_{\mathrm{pO}_{2}}$. Survival in the group with low $\mathrm{S}_{\mathrm{pO}_{2}}$ and low $\mathrm{F}_{\mathrm{IO}_{2}}$ was 


\section{Mechanical Ventilation in Pediatric VV-ECMO}

slightly better than that in the group with high $\mathrm{F}_{\mathrm{IO}_{2}}$ and high $\mathrm{S}_{\mathrm{pO}_{2}}$, but the difference was not statistically significant. It is clear, however, that lower $\mathrm{S}_{\mathrm{pO}_{2}}$ and lower $\mathrm{F}_{\mathrm{IO}_{2}}$ was not worse.

Limiting oxygen therapy with conservative oxygenation goals decreases mortality in critically ill adults. ${ }^{35,40,41}$ Consensus recommendations for target $\mathrm{S}_{\mathrm{pO}_{2}}$ for mechanically ventilated children are graduated, ie, the goal decreases as PEEP increases, with a range of $88-92 \%$ for subjects on $\geq 10 \mathrm{~cm} \mathrm{H}_{2} \mathrm{O}$ PEEP. ${ }^{3}$ There are no consensus guidelines for oxygenation goals in ECMO. We suggest that the oxygen saturation goal should not exceed the 8892\% range suggested for children on mechanical ventilation with high PEEP. Allowing for a lower $\mathrm{S}_{\mathrm{pO}_{2}}$ target and limiting ventilator $\mathrm{F}_{\mathrm{IO}_{2}}$ may be acceptable, given the results of this study. Prospective investigations of conservative ventilator oxygen management and peripheral oxygen saturation targets in children on VV-ECMO are needed to define optimal $\mathrm{S}_{\mathrm{pO}_{2}}$ and $\mathrm{F}_{\mathrm{IO}_{2}}$ targets.

This study has several limitations. The retrospective and observational nature of the study does not allow determination of causation. Because we only evaluated mechanical ventilation strategy during the first $7 \mathrm{~d}$ on ECMO, the impact of ventilator practice later in the ECMO course could not be determined. Given the lack of a standardized approach to mechanical ventilation, it is possible that differences in ventilator management are a surrogate for other differences in care that are center-specific and potentially have an impact on mortality.

\section{Conclusions}

In this study we found variation in ventilator modes and settings for children on VV-ECMO. No mode or pressure setting was associated with mortality, so this study does not support any specific ventilator strategy for ECMO. Ventilator $\mathrm{F}_{\mathrm{IO}_{2}}$ was found to be associated with mortality, even after adjusting for disease severity. A reduction of ventilator $\mathrm{F}_{\mathrm{IO}_{2}}$ may help reduce mortality for pediatric patients requiring VV-ECMO. Further prospective study is needed.

\section{REFERENCES}

1. Schouten LR, Veltkamp F, Bos AP, van Woensel JB, Serpa Neto A, Schultz MJ, Wösten-van Asperen RM. Incidence and mortality of acute respiratory distress syndrome in children: a systematic review and meta-analysis. Crit Care Med 2016;44(4):819-829.

2. Fan E, Brodie D, Slutsky AS. Acute respiratory distress syndrome: advances in diagnosis and treatment. JAMA 2018;319(7):698-710.

3. Khemani RG, Smith LS, Zimmerman JJ, Erickson S, Pediatric Acute Lung Injury Consensus Conference Group. Pediatric acute respiratory distress syndrome: definition, incidence, and epidemiology: proceedings from the Pediatric Acute Lung Injury Consensus Conference. Pediatr Crit Care Med 2015;16(5 Suppl 1):S23-S40.
4. Vasques F, Duscio E, Cipulli F, Romitti F, Quintel M, Gattinoni L. Determinants and prevention of ventilator-induced lung injury. Crit Care Clin 2018;34(3):343-356.

5. Slutsky AS, Ranieri VM. Ventilator-induced lung injury. N Engl J Med 2013;369(22):2126-2136.

6. Schmidt M, Pham T, Arcadipane A, Agerstrand C, Ohshimo S, Pellegrino $\mathrm{V}$, et al. Mechanical ventilation management during ECMO for acute respiratory distress syndrome: an international multicenter prospective cohort. Am J Respir Crit Care Med 2019;200 (8): 1002.

7. Schmidt M, Stewart C, Bailey M, Nieszkowska A, Kelly J, Murphy L, et al. Mechanical ventilation management during extracorporeal membrane oxygenation for acute respiratory distress syndrome: a retrospective international multicenter study. Crit Care Med 2015;43(3):654664.

8. Serpa Neto A, Schmidt M, Azevedo LC, Bein T, Brochard L, Beutel $\mathrm{G}$, et al. Associations between ventilator settings during extracorporeal membrane oxygenation for refractory hypoxemia and outcome in patients with acute respiratory distress syndrome: a pooled individual patient data analysis: Mechanical ventilation during ECMO. Intensive Care Med 2016;42(11):1672-1684.

9. Chiu LC, Hu HC, Hung CY, Chang CH, Tsai FC, Yang CT, et al. Dynamic driving pressure associated mortality in acute respiratory distress syndrome with extracorporeal membrane oxygenation. Ann Intensive Care 2017;7(1):12.

10. Marhong JD, Munshi L, Detsky M, Telesnicki T, Fan E. Mechanical ventilation during extracorporeal life support (ECLS): a systematic review. Intensive Care Med 2015;41(6):994-1003.

11. Alapati D, Aghai ZH, Hossain MJ, Dirnberger DR, Ogino MT, Shaffer TH, Extracorporeal Life Support Organization Member Centers. Lung rest during extracorporeal membrane oxygenation for neonatal respiratory failure-practice variations and outcomes. Pediatr Crit Care Med 2017;18(7):667-674.

12. Meade MO, Cook DJ, Guyatt GH, Slutsky AS, Arabi YM, Cooper DJ, et al. Ventilation strategy using low tidal volumes, recruitment maneuvers, and high positive end-expiratory pressure for acute lung injury and acute respiratory distress syndrome: a randomized controlled trial. JAMA 2008;299(6):637-645

13. Khemani RG, Conti D, Alonzo TA, Bart RD3rd, Newth CJ. Effect of tidal volume in children with acute hypoxemic respiratory failure. Intensive Care Med 2009;35(8):1428-1437.

14. Brower RG, Matthay MA, Morris A, Schoenfeld D, Thompson BT, Wheeler A. Ventilation with lower tidal volumes as compared with traditional tidal volumes for acute lung injury and the acute respiratory distress syndrome. N Engl J Med 2000;342(18):1301-1308.

15. Dalton HJ, Macrae DJ, Pediatric Acute Lung Injury Consensus Conference Group. Extracorporeal support in children with pediatric acute respiratory distress syndrome: proceedings from the Pediatric Acute Lung Injury Consensus Conference. Pediatr Crit Care Med 2015;16(5 Suppl 1):S111-S117.

16. Yehya N, Dominick CL, Connelly JT, Davis DH, Minneci PC, Deans $\mathrm{KJ}$, et al. High-frequency percussive ventilation and bronchoscopy during extracorporeal life support in children. ASAIO J 2014;60 (4):424-428

17. Peek GJ, Mugford M, Tiruvoipati R, Wilson A, Allen E, Thalanany $\mathrm{MM}$, et al. Efficacy and economic assessment of conventional ventilatory support versus extracorporeal membrane oxygenation for severe adult respiratory failure (CESAR): a multicentre randomised controlled trial. Lancet 2009;374(9698):1351-1363.

18. Keszler M, Subramanian KN, Smith YA, Dhanireddy R, Mehta N, Molina B, et al. Pulmonary management during extracorporeal membrane oxygenation. Crit Care Med 1989;17(6):495-500.

19. Brodie D, Bacchetta M. Extracorporeal membrane oxygenation for ARDS in adults. N Engl J Med 2011;365(20):1905-1914. 


\section{Mechanical Ventilation in Pediatric VV-ECMO}

20. Marhong JD, Telesnicki T, Munshi L, Del Sorbo L, Detsky M, Fan E. Mechanical ventilation during extracorporeal membrane oxygenation. An international survey. Ann Am Thorac Soc 2014;11(6):956-961.

21. Zakhary B, Fan E, Slutsky A. Pro: should patients with acute respiratory distress syndrome on veno-venous extracorporeal membrane oxygenation have ventilatory support reduced to the lowest tolerable settings? Crit Care Med 2019

22. Bailly DK, Reeder RW, Zabrocki LA, Hubbard AM, Wilkes J, Bratton SL, et al. Development and validation of a score to predict mortality in children undergoing extracorporeal membrane oxygenation for respiratory failure: pediatric pulmonary rescue with extracorporeal membrane oxygenation prediction score. Crit Care Med 2017;45(1):e58-e66.

23. Barbaro RP, Boonstra PS, Paden ML, Roberts LA, Annich GM, Bartlett RH, et al. Development and validation of the pediatric risk estimate score for children using extracorporeal respiratory support (Ped-RESCUERS). Intensive Care Med 2016;42(5):879-888.

24. Soler YA, Nieves-Plaza M, Prieto M, García-De Jesus R, SuárezRivera M. Pediatric risk, injury, failure, loss, end-stage renal disease score identifies acute kidney injury and predicts mortality in critically ill children: a prospective study. Pediatr Crit Care Med 2013;14(4): e189-e195.

25. Kidney Diseases: Improving Global Outcomes (KDIGO) Acute Kidney Injury Work Group. KDIGO Clinical Practice Guideline for Acute Kidney Injury. Kidney Int Suppl 2012;2:1-138.

26. Zabrocki LA, Brogan TV, Statler KD, Poss WB, Rollins MD, Bratton SL. Extracorporeal membrane oxygenation for pediatric respiratory failure: Survival and predictors of mortality. Crit Care Med 2011;39 (2):364-370

27. Combes A, Hajage D, Capellier G, Demoule A, Lavouë S, Guervilly $\mathrm{C}$, et al. Extracorporeal membrane oxygenation for severe acute respiratory distress syndrome. N Engl J Med 2018;378(21):1965-1975.

28. Camporota L, Nicoletti E, Malafronte M, De Neef M, Mongelli V, Calderazzo MA, et al. International survey on the management of mechanical ventilation during ECMO in adults with severe respiratory failure. Minerva Anestesiol 2015;81(11):1170-1183.

29. Modrykamien AM, Hernandez OO, Im Y, Walters RW, Schrader CL, Smith LE, Lima B. Mechanical ventilation in patients with the acute respiratory distress syndrome and treated with extracorporeal membrane oxygenation: impact on hospital and 30 day postdischarge survival. ASAIO J 2016;62(5):607-612.

30. Keszler M, Ryckman FC, McDonald JVJr., Sweet LD, Moront MG, Boegli MJ, et al. A prospective, multicenter, randomized study of high versus low positive end-expiratory pressure during extracorporeal membrane oxygenation. J Pediatr 1992;120(1):107-113.

31. de Jager P, Burgerhof JG, van Heerde M, Albers MJ, Markhorst DG, Kneyber MC. Tidal volume and mortality in mechanically ventilated children: a systematic review and meta-analysis of observational studies. Crit Care Med 2014;42(12):2461-2472.

32. Kneyber MC, Zhang H, Slutsky AS. Ventilator-induced lung injury: similarity and differences between children and adults. Am J Respir Crit Care Med 2014;190(3):258-265.

33. Rozenwajg S, Guihot A, Franchineau G, Lescroat M, Brechot N, Hékimian $\mathrm{G}$, et al. Ultra-protective ventilation reduces biotrauma in patients on venovenous extracorporeal membrane oxygenation for severe respiratory distress syndrome. Crit Care Med 2019;47(11): 1505-1512.

34. Camporota L, Caricola EV, Bartolomeo N, Di Mussi R, Wyncoll DLA, Meadows CIS, et al. Lung recruitability in severe acute respiratory distress syndrome requiring extracorporeal membrane oxygenation. Crit Care Med 2019;47(9):1177-1183.

35. Chu DK, Kim LH, Young PJ, Zamiri N, Almenawer SA, Jaeschke R, et al. Mortality and morbidity in acutely ill adults treated with liberal versus conservative oxygen therapy (IOTA): a systematic review and meta-analysis. Lancet 2018;391(10131):1693-1705.

36. Ray PD, Huang BW, Tsuji Y. Reactive oxygen species (ROS) homeostasis and redox regulation in cellular signaling. Cell Signal 2012; 24(5):981-990.

37. Pannu SR. Too much oxygen: hyperoxia and oxygen management in mechanically ventilated patients. Semin Respir Crit Care Med 2016; 37(1):16-22

38. Douglas ME, Downs JB, Dannemiller FJ, Hodges MR, Munson ES. Change in pulmonary venous admixture with varying inspired oxygen. Anesth Analg 1976;55(5):688-695.

39. O'Brien J. Absorption atelectasis: incidence and clinical implications. AANA J 2013;81(3):205-208

40. Suzuki S, Eastwood GM, Goodwin MD, Noë GD, Smith PE, Glassford N, et al. Atelectasis and mechanical ventilation mode during conservative oxygen therapy: a before-and-after study. J Crit Care 2015;30(6):1232-1237.

41. Girardis M, Busani S, Damiani E, Donati A, Rinaldi L, Marudi A, et al. Effect of conservative vs conventional oxygen therapy on mortality among patients in an intensive care unit: the oxygen-ICU randomized clinical trial. JAMA 2016;316(15):1583-1589.

This article is approved for Continuing Respiratory Care Education credit. For information and to obtain your CRCE

(free to AARC members) visit www.rcjournal.com 